\title{
A Double Blind Randomized Trial to Compare the Effects of Eprosartan and Enalapril on Blood Pressure, Platelets, and Endothelium Function in Patients With Essential Hypertension
}

\author{
Hsin-Bang LeU, ${ }^{1}$ MD, Ming-Ji ChARng, ${ }^{1} \mathrm{MD}$, and Philip Yu-An Ding, ${ }^{1}$ MD
}

\begin{abstract}
SUMMARY
The renin-angiotensin system is the major contributor to development of hypertension, atherosclerosis, and many other cardiovascular diseases. Angiotensin II, one of the main effectors of this system, contributes to the pathogenesis of hypertension and plays an important role in monocyte, platelet, and endothelium interactions. The effects on platelet and endothelial function, either by angiotensin converting enzyme inhibitors or angiotensin receptor antagonists, are still not well understood.

A double-blind, randomized, prospective trial of either enalapril (10-20 mg daily) or eprosartan (400-800 mg daily) over a 10-week period was conducted in 42 patients (27 males, 15 females). Platelet activation was evaluated by measuring platelet factor 4 (PF4 ), beta-thromboglobulin ( $\beta$-TG), the ratio of platelet factor 4 to beta-thromboglobulin, and endothelial function by measuring total plasma nitrate levels, von Willebrand factor (vWF) levels, and blood flow using venous occlusive plethysmography.

After a 10-week treatment with enalapril or eprosartan, the sitting blood pressure in both the enalapril group (from $152.2 \pm 18.7 \mathrm{mmHg}$ to $141.9 \pm 23.5 \mathrm{mmHg}, P<0.05$ ) and eprosartan group (from $151 \pm 10.0 \mathrm{mmHg}$ to $142.3 \pm 12.9 \mathrm{mmHg}, P<0.05$ ) was significantly reduced. Significant diastolic blood pressure (DPB) reduction (from $94 \pm 8.7$ to $84.5 \pm 9.6 \mathrm{mmHg}, P<0.05)$ and a greater DBP reduction response were found in the eprosartan group (63\% in eprosartan versus $25 \%$ in enalapril). Additionally, dose-dependent reductions in the indices of platelet activation and endothelial dysfunction were observed in patients administered high dose treatments of eprosartan and enalapril, and the beneficial effects of these agents were not correlated with the reduction of blood pressure using both agents.

Eprosartan is effective and well-tolerated in the treatment of mid-to-moderate hypertension, and the DBP response reduction to eprosartin was better than that to enalapril. A high dose of either eprosartan or enalapril significantly decreased the indices of platelet activation and endothelial dysfunction in hypertensive patients. The benefits of both
\end{abstract}

From the ${ }^{1}$ Division of Cardiology, Taipei Veterans General Hospital and National Yang-Ming University, Taipei, Taiwan, R.O.C.

Address for correspondence: Ming-Ji Charng, MD, Division of Cardiology, Taipei Veterans General Hospital, No 201, Sec

2, Shin-Pai Road, Taipei, Taiwan.

This work was supported by grants from the National Science Council of Taiwan (NSC-90-2314-B-075-048)

Received for publication June 20, 2003.

Revised and accepted January 19, 2004. 
agents cannot be explained solely by their antihypertensive effects and possibly may be mediated through their unique effect on angiotensin blockade. (Jpn Heart J 2004; 45: 623635)

Key words: Angiotensin receptor antagonist, Platelet factor 4 (PF4), Beta-thromboglobulin $(\beta$-TG), von Willebrand factor (vWF), Venous occlusive plethysmography

HyPertension is one of the major risk factors for cardiovascular diseases, such as coronary artery disease, stroke, and renal failure. Because hypertension places patients at increased risk of target organ damage, it is widely accepted that to reduce cardiovascular morbidity and mortality, blood pressure must be controlled, and therefore antihypertensive agents should be administered.

The renin-angiotensin system (RAS), which is a complex system of enzymes, peptides, and proteins, plays a central role in the maintenance of blood pressure, extracellular fluid volume, and electrolyte balance. Medication for this complex system, such as angiotensin-converting enzyme inhibitors (ACEIs), has been reported to reduce the incidence of recurrent myocardial infarction, unstable angina or sudden death in patients with previous myocardial infarction and left ventricular dysfunction. ${ }^{1,2)}$ ACE inhibitors are believed to decrease coronary vasoconstriction by inhibiting the production of angiotensin-II and decreasing degradation of bradykinin, which may increase nitric oxide production and be heavily involved in the regulation of endothelial function. ${ }^{3)}$ The anti-ischemic benefits of ACE inhibitors might also be explained by their possible influence on serum levels of prostacyclin and tissue plasminogen activator inhibitors, and by their ability to improve hypercoagulation status. ${ }^{4,5)}$

Recent observations have revealed that angiotensin II, the main effector of the renin-angiotensin system and an important effector in the development of hypertension and atherosclerosis, ${ }^{6}$ facilitates the recruitment of macrophages/ monocytes into the vessel wall by intercellular cytokines, such as monocyte chemoattractant protein-1 (MCP-1) and vascular adhesion molecule-1 (VCAM1). ${ }^{7.8)}$ Angiotensin II receptor antagonists, a novel class of antihypertensive agents, offers a new opportunity to manipulate the RAS for blood pressure control. The efficacy of these agents for blood pressure control is similar to that of ACE inhibitors, and their potential antithrombotic activities are considerable. Clinical observation also revealed that angiotensin-II receptor blockade could blunt the development of atherosclerosis in the absence of a hypotensive effect. ${ }^{9)}$ The reported effect of angiotensin as a prothrombotic factor might lead one to predict that angiotensin II antagonists would retard thromboembolic cardiovascular complications. So inhibition of the renin-angiotensin system, either with angiotensin-converting enzyme inhibitors or angiotensin II receptor antagonists, 
could have anti-ischemic effects and retard the thrombotic process/hypercoagulable state. However, the effects of angiotensin II receptor antagonists on platelet and endothelium function are unclear. Mildly elevated beta-thromboglobulin $(\beta$ TG) after angiotensin II infusion in healthy volunteers has been reported. ${ }^{22)}$ Measurement of plasma levels of two secreted platelet proteins $(\beta$-TG and platelet factor 4$)^{23)}$ and the ratio of $\beta$-TG to PF4 have been suggested as a means for detecting increased platelet activation in vivo. ${ }^{23)}$ Additionally, plasma total nitrates, von Willebrand factor (vWF), ${ }^{12,13)}$ and venous occlusive plethysmography ${ }^{15)}$ have been considered as indices of endothelial function. The aim of our research was to perform a double-blind randomized study to evaluate whether platelet or endothelial function could be influenced by inhibition of the reninangiotensin-aldosterone (RAA) system with an ACE inhibitor (enalapril) and an angiotensin II antagonist (eprosartan), as well as blood pressure reduction by the above medications. In addition, we sought to study the relationship between blood pressure reduction and changes in the index of endothelial function, and platelet activation with drug therapy.

\section{Methods}

Patient population: This double blind study originally included 51 outpatients who had mild to moderate essential hypertension (average sitting DBP $\geq 95$ $\mathrm{mmHg}$ and $\leq 114 \mathrm{mmHg}$ ). Half of the 51 patients (25 patients) had never been treated for hypertension; the other 26 had been treated with calcium channel blockers (12 patients), alpha-blockers ( 7 patients), and beta-blockers ( 7 patients). Baseline characteristics of the previously treated and untreated patients were not significantly different. The exclusion criteria included pregnancy or lactation, secondary hypertension, bilateral renal artery stenosis, angina pectoris, chronic obstructive pulmonary disease (COPD), heart failure or history of heart failure, second or third degree atrioventricular (AV) block, clinically relevant arrhythmia or valvular heart disease, uncontrolled diabetes mellitus, neoplasm, and eprosartan or ACE inhibitor intolerance or withdrawal during a washout period. Patients with evidence of chronic liver disease (alanine transaminase [ALT] $\geq 80 \mathrm{IU} / \mathrm{L}$, aspartate transaminase $[\mathrm{AST}] \geq 90 \mathrm{IU} / \mathrm{L}$ and total bilirubin $\geq 3.2 \mathrm{mg} / \mathrm{dL}$ ), creatinine $>2.5 \mathrm{mg} / \mathrm{dL}$, or obesity (body mass index $>28$ ) were also excluded from the study.

This was a randomized, double-blind, active control and parallel group study. The same drug was used throughout the study, and the study followed the guidelines of the institutional review board at Taipei Veterans General Hospital. The research ethics committee approved this study, and all subjects gave written informed consent at the time of enrollment. 
Treatment: After a two-week washout period (considered long enough to remove the effects of previous medications) for those who were already on antihypertensive agents, 26 patients were randomly assigned to the eprosartan group and 25 to the enalapril group (Figure 1). Treatment included a six-week dose titration period to identify the optimal dose of eprosartan $(400,600$, or $800 \mathrm{mg}$ once daily) or enalapril $(5,10$, or $20 \mathrm{mg}$ once daily), a four-week period of maintenance and then titration. The total treatment period was 10 weeks. Following the initial two weeks of washout, the patients were randomly separated into two equally sized groups to receive either eprosartan $400 \mathrm{mg}$ once daily or enalapril 5 $\mathrm{mg}$ once daily. After treatment for two weeks, patients whose blood pressure was inadequately controlled (mean sitting diastolic $\mathrm{BP} \geq 90 \mathrm{mmHg}$ ) received upward titration to eprosartan $600 \mathrm{mg}$ daily or enalapril $10 \mathrm{mg}$ daily. The maximal titration dosage was eprosartan $800 \mathrm{mg}$ or enalapril $20 \mathrm{mg}$ daily according to the twoweek follow-up sessions during the initial six-week titration period.

Platelet activation indices: Five milliliters of whole blood sample was collected into a tube containing disodium ethylenediamine tetraacetate (EDTA-Na2) and immediately centrifuged at $2000 \mathrm{~g}$ at $4^{\circ} \mathrm{C}$ for 20 minutes. Changes in platelet activation indices, such as plasma beta-thromboglobulin ( $\beta$-TG) and platelet factor 4 (PF-4), were measured using a commercially available enzyme-linked immunosorbent assay (ELISA) (Asserachrom ${ }^{\circledR}$, Diagnostica Stago, France). To avoid

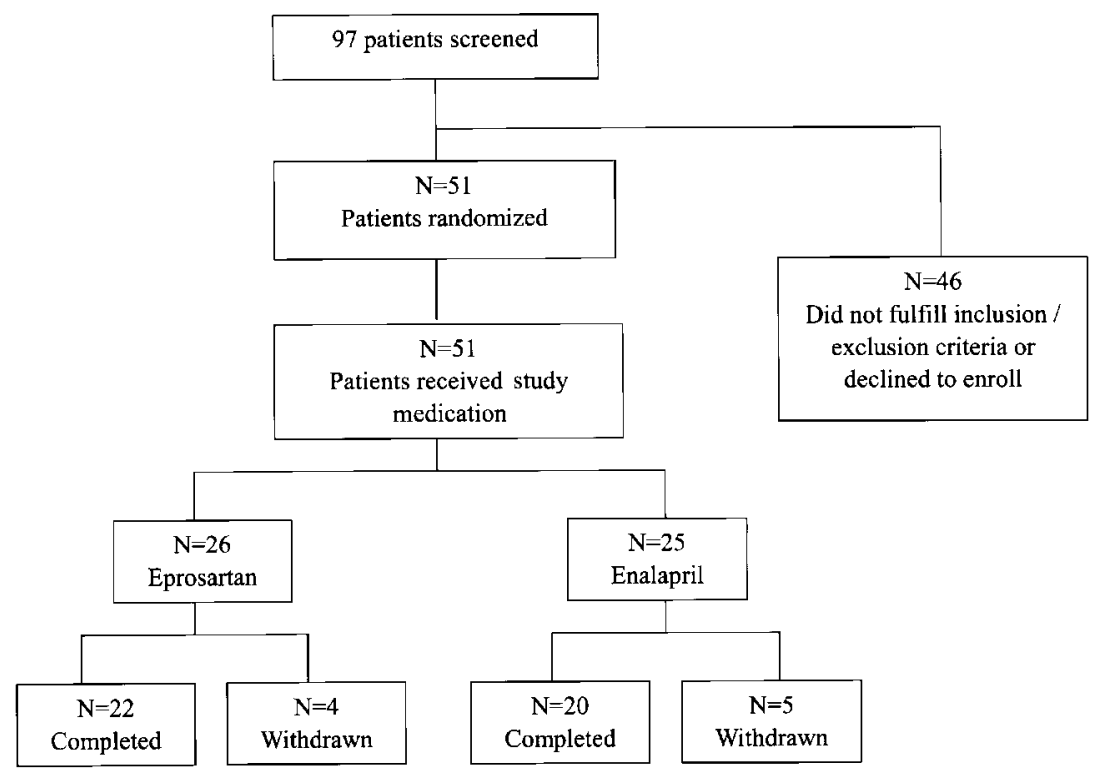

Figure 1. Study Profile. 
the possible error of measuring $\beta$-TG and PF-4, the beta-thromboglobulin $(\beta$-TG) to platelet factor 4 (PF-4) ratio was also measured as previously described by Gomi and Ding. ${ }^{10,11)}$ All samples were analyzed in duplicate by an individual blind to the treatment protocol.

Measurement of nitric oxide and von Willebrand factor: In addition, the parameters of endothelial function, nitric oxide (NO), and von Willebrand factor (vWF), which previously were reported to be abnormally high in patients with hypertension, ${ }^{12,13)}$ were also evaluated. Plasma total nitric oxide was determined using a nitric oxide analyzer $\mathrm{NOA}^{\mathrm{TM}} 280$ System (Sievers Instruments, Boulder, CO, USA). Total nitric oxide (NO) and von Willebrand factor were determined using commercially available enzyme-linked immunosorbent assays (ELISA) (R\&D Systems, Minneapolis, MN, USA), and all samples were analyzed in duplicate by an individual blind to the treatment protocol.

Venous occlusive plethysmography: Furthermore, on the basis of the concept that the volume of arterial flow is proportional to the changes in the forearm circumference when venous outflow is occluded ${ }^{14)}$ and highly related to endothelial function, we performed venous occlusive plethysmography as previously described by Endo, et $a l^{15)}$ on the dominant, usually right forearm to follow forearm reactive hyperemia changes after enalapril or eprosartan treatment. The blood pressure measurements were obtained with the patient in the seated position using a standard mercury sphygmomanometer with a cuff of the appropriate size. Measurements were taken in the morning before daily medication and after at least 15 minutes of rest in a quiet room. Three successful measurements (lasting one minute each) were taken and averaged. Blood samples and venous occlusive plethysmography data were collected prior to treatment and also after the 10 weeks of antihypertensive treatment.

Statistical analysis: Data are expressed as the mean \pm SD. Comparisons between the eprosartan and enalapril groups were made using the unpaired Student's $t$-test for parametric and the Mann-Whitney $U$ test for nonparametric distributions. A paired Student's $t$-test or paired Wilcoxon's test was used to analyze the efficacy on the basis of pre- versus posttreatment comparison. Fisher's exact test was used to determine the difference in efficacy and incidence of adverse events between treatments. To further investigate the effect of treatment on biochemical markers, the Kruskal-Wallis test was performed to assess the percent change in biochemical markers of various dosages after treatment in each group. In addition, the impact of the treatment efficacy on biochemical markers was assessed according to the magnitude of SBP reduction between both groups. The correlation between the change in BP reduction and measured parameters after antihypertensive treatment was assessed by the Spearman correlation coefficient. A $P$ value $<0.05$ was considered statistically significant. 


\section{Results}

A total of 97 patients were evaluated for eligibility. Fifty-one patients fulfilled the inclusion criteria, and 42 (27 males and 15 females, mean age, $58.6 \pm$ 10.8 years with a mean blood pressure of $151.6 \pm 14.6 \mathrm{mmHg}$ and $108.0 \pm 9.0$ $\mathrm{mmHg}$, respectively) were studied. Twenty-two patients were treated with eprosartan and 20 with enalapril. Withdrawal from the study was due to loss of follow-up (three in the eprosartan group and three in the enalapril groups), lack of efficacy (one in the eprosartan group and one in the enalapril group), and other causes (one in the enalapril group) (Figure 1). There were no statistically significant clinical differences between these two groups (Table I). After 10 weeks of antihypertensive therapy, systolic and diastolic BP was significantly reduced $(151 \pm 10.0$ to $142.3 \pm 12.9 \mathrm{mmHg}, 94 \pm 8.7$ to $84.5 \pm 9.6 \mathrm{mmHg}, P<0.05)$ in patients receiving treatment with eprosartan (Table II) (Figure 2); however, in those receiving enalapril treatment, only systolic BP was reduced significantly from $152.2 \pm 18.7$ to $141.9 \pm 23.5 \mathrm{mmHg}(P<0.05)$ (Table II) (Figure 2). There were more patients in the eprosartan group $(14,63 \%)$ than in the enalapril group $(5,25 \%)$ that achieved a sitting DBP of less than $90 \mathrm{mmHg}$ at visit 6 (week 10), and the difference was statistically significant $(P=0.02$, Fisher's exact test) (Figure 3$)$. There were no statistically significant changes in plasma beta-thromboglobulin ( $\beta$-TG), platelet factor 4 (PF-4), total nitric oxide (NO), the ratio of $\beta$-TG to $\mathrm{PF}-4$, and von Willebrand factor (vWF) among the eprosartan and enalapril groups (Table III), nor in endothelial function detected by venous occlusive plethysmography (data not shown). No serious clinical or laboratory adverse event was observed among the study populations. The number of adverse events

Table I. Characteristics of the Study Population

\begin{tabular}{lccc}
\hline & $\begin{array}{c}\text { Eprosartan } \\
(n=22)\end{array}$ & $\begin{array}{c}\text { Enalapril } \\
(n=20)\end{array}$ & $P$ value \\
\hline Age, y & $59.18 \pm 7.07$ & $57.65 \pm 10.12$ & NS \\
Male, $(\%)$ & $13(60)$ & $14(70)$ & NS \\
Height, cm & $160.36 \pm 8.16$ & $163.43 \pm 7.96$ & NS \\
Weight, $\mathrm{kg}$ & $67.20 \pm 9.68$ & $74.40 \pm 13.31$ & $\mathrm{NS}$ \\
BMI, $\mathrm{kg} / \mathrm{m}^{2}$ & $26.04 \pm 2.33$ & $27.84 \pm 4.46$ & $\mathrm{NS}$ \\
SBP, $\mathrm{mmHg}$ & $151.05 \pm 9.99$ & $152.20 \pm 18.66$ & $\mathrm{NS}$ \\
DBP, $\mathrm{mmHg}$ & $94.73 \pm 8.67$ & $97.65 \pm 10.89$ & $\mathrm{NS}$ \\
Glucose, $\mathrm{mg} / \mathrm{dL}$ & $97.41 \pm 9.87$ & $105.15 \pm 34.59$ & $\mathrm{NS}$ \\
BUN, mg/dL & $15.41 \pm 4.69$ & $14.85 \pm 4.12$ & $\mathrm{NS}$ \\
Creatinine, mg/dL & $1.00 \pm 0.27$ & $0.99 \pm 0.15$ & $\mathrm{NS}$ \\
Total cholesterol, mg/dL & $212.27 \pm 32.06$ & $211.10 \pm 39.83$ & $\mathrm{NS}$ \\
Triglyceride, $\mathrm{mg} / \mathrm{dL}$ & $118.18 \pm 46.27$ & $133.85 \pm 51.09$ & $\mathrm{NS}$ \\
\hline
\end{tabular}

Data are given as mean \pm SD. BMI indicates body mass index; $\mathrm{SBP}=$ systolic blood pressure; DBP = diastolic blood pressure; $\mathrm{BUN}=$ blood urea nitrogen. 
Table II. Changes in Systolic and Diastolic BP After 10 Weeks of Eprosartan or Enalapril Therapy

\begin{tabular}{|c|c|c|c|c|c|c|}
\hline & \multicolumn{3}{|c|}{$\begin{array}{c}\text { Eprosartan } \\
(n=22)\end{array}$} & \multicolumn{2}{|r|}{$\begin{array}{c}\text { Enalapril } \\
(n=20)\end{array}$} & \multirow[b]{2}{*}{$P$} \\
\hline & Pre-treatment & Post-treatment & $P$ & Pre-treatment & Post-treatment & \\
\hline SBP, mmHg & $151 \pm 10.0$ & $142.3 \pm 12.9$ & 0.017 & $152.2 \pm 18.7$ & $141.9 \pm 23.5$ & 0.032 \\
\hline $\mathrm{DBP}, \mathrm{mmHg}$ & $94 \pm 8.7$ & $84.5 \pm 9.6$ & 0.006 & $97.7 \pm 10.9$ & $92.85 \pm 11.4$ & NS \\
\hline
\end{tabular}

Data are given as the mean $\pm \mathrm{SD} ; \mathrm{SBP}=$ systolic blood pressure; $\mathrm{DBP}=$ diastolic blood pressure.
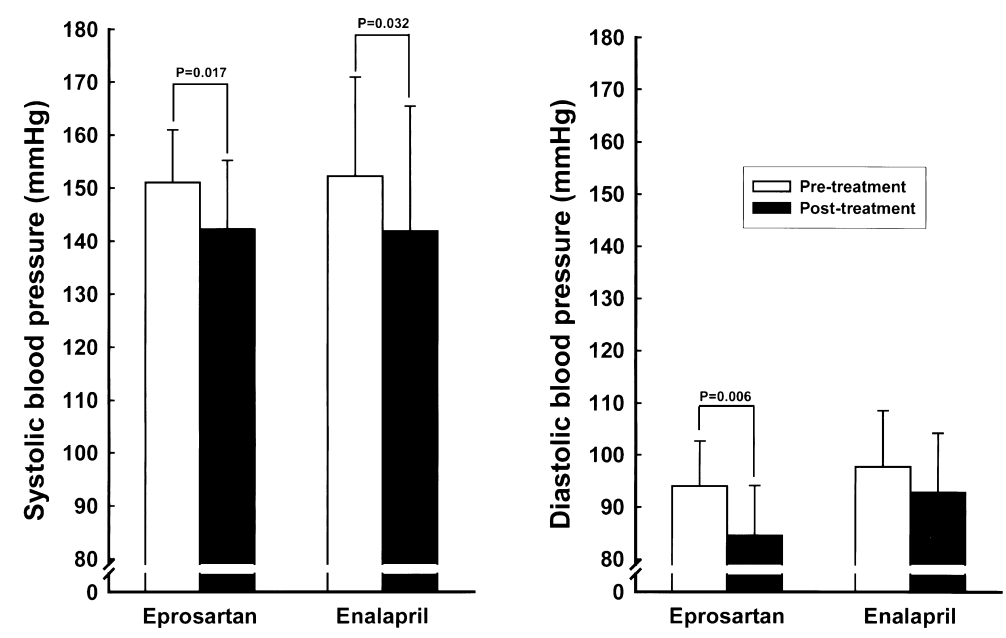

Figure 2. The changes in systolic and diastolic blood pressure in patients with essential hypertension after eprosartan or enalapril treatment. Data are expressed as mean $\pm \mathrm{SD}$.

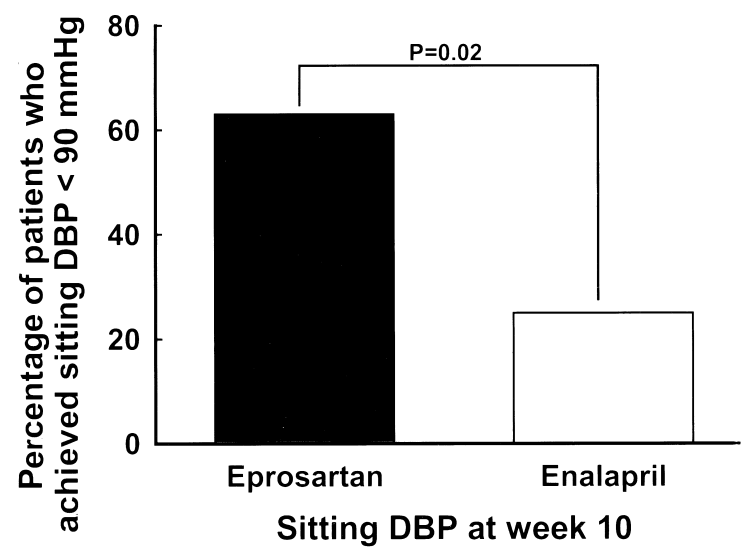

Figure 3. The percentage of patients with sitting diastolic BP $<90 \mathrm{mmHg}$ after 10 weeks of treatment. 
Table III. Response of Measured Parameters to Therapy With Eprosartan and Enalapril

\begin{tabular}{lcccccc}
\hline & \multicolumn{2}{c}{$\begin{array}{c}\text { Eprosartan } \\
(n=22)\end{array}$} & & & \multicolumn{2}{c}{$\begin{array}{c}\text { Enalapril } \\
(n=20)\end{array}$} \\
& Pre-treatment & Post-treatment & $P$ & Pre-treatment & Post-treatment & $P$ \\
\cline { 2 - 7 } & $74.3 \pm 47.4$ & $74.6 \pm 48.9$ & 0.73 & $61.6 \pm 34.5$ & $76.0 \pm 68.7$ & 0.58 \\
$\mathrm{NO}_{2}{ }^{-}+\mathrm{NO}_{3}-(\mu \mathrm{M})$ & $1280.3 \pm 546.6$ & $1221.9 \pm 679$ & 0.17 & $1145.9 \pm 636.8$ & $1245.6 \pm 795.0$ & 0.22 \\
$\mathrm{vWF}(\mathrm{mU} / \mathrm{mL})$ & $6509 \pm 3414.8$ & $5160.6 \pm 3869.7$ & 0.25 & $5821.9 \pm 3516.6$ & $5789.9 \pm 3946.6$ & 0.74 \\
$\beta$-TG $(\mathrm{IU} / \mathrm{mL})$ & $580.4 \pm 362.4$ & $557.1 \pm 392.7$ & 0.98 & $515.5 \pm 340.5$ & $623.4 \pm 454.1$ & 0.19 \\
$\mathrm{PF} 4(\mathrm{IU} / \mathrm{mL})$ & $11.4 \pm 3.2$ & $9.6 \pm 4.4$ & 0.13 & $11.7 \pm 3.8$ & $9.4 \pm 4.4$ & 0.08 \\
$\beta$-TG/PF4 & & & & & &
\end{tabular}

$* P<0.05$, Values are the mean $\pm \mathrm{SD} ; \mathrm{vWF}=$ von Willebrand factor; $\beta$-TG $=\beta$-thromboglobulin; $\mathrm{PF} 4=$ platelet factor $4, \beta$-TG/PF4 $=$ the ratio of $\beta$-thromboglobulin to platelet factor 4 .

reported in each treatment group did not differ substantially. There were more reported cases of cough in the enalapril group than in the eprosartan group (25\% versus $15 \%$ ). Additionally, to assess the effects of the individual pharmaceutical agents, the relationship between biochemical marker changes and different dosages to achieve optimal BP control are demonstrated in Table IV. The baseline characteristics of patients with different dosages were similar (data not shown). Significant decreases in vWF $(P=0.001)$ and $\beta$-TG/PF-4 $(P=0.023)$ and a borderline significant decrease in $\beta$-TG $(P=0.07)$ were observed in patients taking eprosartan $800 \mathrm{mg}$ daily. On the other hand, a significant reduction in $\beta$-TG/PF4 $(P=0.05)$ was found in patients taking enalapril $20 \mathrm{mg}$ daily. Furthermore, we compared the percent change of these markers based on the level of blood pressure reduction, including nonresponders, $\leq 15 \% \mathrm{SBP}$ reduction, and $>15 \% \mathrm{SBP}$ reduction. There were no differences in the baseline characteristics between these patients. There was no significant difference observed in the change of values of biochemical markers between eprosartan and enalapril at an almost identical level of blood pressure reduction, except a significantly greater reduction in vWF $(P=0.004)$ among patients taking eprosartan (Table V). Although not statistically significant, eprosartan tended to have a greater reduction in platelet activation and endothelial damage than enalapril in patients with significant BP reduction after treatment. In addition, we also evaluated the correlation between the percent change in BP reduction and measured parameters. There was no significant correlation between the extent of BP reduction and other variables in either group (Table VI). 
Table VI. Correlation of BP Reduction and Changes in Measured Parameters in Eprosartan and Enalapril Groups

\begin{tabular}{lccrc}
\hline & \multicolumn{2}{c}{ Eprosartan } & \multicolumn{2}{c}{ Enalapril } \\
\cline { 2 - 5 } & $\rho$ & $P$ & \multicolumn{1}{c}{$\rho$} & \multicolumn{1}{c}{$P$} \\
\hline $\mathrm{NO}_{2}{ }^{-}+\mathrm{NO}_{3}-(\mu \mathrm{M})$ & 0.05 & 0.824 & -0.153 & 0.519 \\
$\mathrm{vWF}(\mathrm{mU} / \mathrm{mL})$ & 0.224 & 0.316 & 0.063 & 0.791 \\
$\beta-\mathrm{TG}(\mathrm{IU} / \mathrm{mL})$ & 0.372 & 0.088 & -0.192 & 0.416 \\
$\mathrm{PF} 4(\mathrm{IU} / \mathrm{mL})$ & 0.312 & 0.157 & -0.222 & 0.352 \\
$\beta$-TG/PF4 & 0.186 & 0.408 & -0.018 & 0.94 \\
\hline
\end{tabular}

$\mathrm{vWF}=$ von Willebrand factor $\beta$-TG $=\beta$-thromboglobulin; $\mathrm{PF} 4=$ platelet factor $4, \beta$-TG/PF4 $=$ the ratio of $\beta$ thromboglobulin to platelet factor 4 .

\section{DISCUSSION}

This randomized, double-blind study in Chinese patients with mild to moderate essential hypertension demonstrated that eprosartan (an angiotensin II receptor blocker) $400-800 \mathrm{mg}$ once daily is well-tolerated and effective at reducing seated systolic blood pressure (SBP) and diastolic blood pressure (DBP). A similar magnitude of SBP reduction was also found in patients taking enalapril 5$20 \mathrm{mg}$. A significant dose-dependent reduction in measured parameters was observed in patients undergoing high dose therapy with eprosartan and enalapril, and the beneficial effects of these agents were not correlated with the extent of blood pressure reduction in either agent.

The clinical efficacy of eprosartan for blood pressure control has been shown in other placebo-controlled trials and comparative studies. ${ }^{16,17)}$ In the present study, eprosartan was as effective as ACE inhibitors in lowering blood pressure and was even better in terms of the responder rate. Similar to other clinical trials comparing ACE inhibitors with AT-1-receptor antagonists, patients with ACE inhibitors had more side effects, mainly coughing, which is related to bradykinin activation. ${ }^{18)}$

Beyond vasoconstriction, angiotensin II (Ang II) plays an important role in the pathogenesis of ischemic cardiovascular disease and has atherogenic properties. ${ }^{6,19)}$ It has been suggested that interruption of the renin-angiotensin system can forestall the development of atherosclerosis, and both ACE inhibitors and angiotensin receptor antagonists have been shown to have an anti-atherosclerosis effect. ${ }^{9,19-21)}$ Mildly elevated beta-thromboglobulin ( $\beta$-TG) after angiotensin II infusion in healthy volunteers was reported previously. ${ }^{22}$ Measurement of plasma levels of two secreted platelet proteins ( $\beta$-TG and platelet factor 4$)^{23)}$ and 
the ratio of $\beta$-TG to PF4 have been suggested as a means for detecting increased platelet activation in vivo. ${ }^{23)}$ In the present study, we have demonstrated that eprosartan significantly decreased the levels of platelet activation $(\beta$-TG, PF4 and $\beta$ TG/PF4) and improved endothelial dysfunction (vWF) at the highest dosage level. Similarly, enalapril decreased $\beta$-TG and $\beta$-TG/PF4 at relatively high dosage levels. Interestingly, the benefit of reduction of platelet activation and endothelial damage was not correlated with the extent of BP reduction, suggesting that the potential antiatherosclerotic effect of these agents manipulating the RAS was not entirely through their antihypertensive effects alone. Furthermore, the administration of an AT1 antagonist with eprosartan was associated with a significant reduction in platelet activation and endothelial dysfunction that was greater than during ACE inhibition. These beneficial effects of AT1 antagonism and ACE inhibition would therefore appear to be mediated principally through blocking the effect of angiotensin II. Similar findings were also observed in CHF patients with losartan and enalapril treatment. ${ }^{24)}$ Several possibilities have been proposed to explain the insignificant changes in measured parameters after treatment, unless during high dose treatment. Elevated von Willebrand factor and sP-selectin among hypertensive patients with target organ damage (TOD) ${ }^{13)}$ has been reported previously. One possibility is that our patient population had relatively mild to moderate hypertension instead of TOD, indicating that subtle changes in endothelial dysfunction were not detected by measuring the parameters we selected. Other possibilities included inadequate dosage and treatment length to exert the beneficial effects on those parameters. In addition, Nunez, et al demonstrated that only some AT(1)-receptor antagonists reduce thromboxane A2dependent human platelet activation, which is not a feature common to all AT(1) antagonists. ${ }^{25)}$ Moton, et al also showed that some AT-1-receptor antagonists reduce in vitro thromboxane A2-dependent activation of human platelets independent of angiotensin II involvement. ${ }^{26)}$ Thus, it is possible that some AT-1 receptor antagonists or ACEI may have distinct effects on platelet and endothelial function.

Although the sample size in our present study is relative small, it is similar to those reported previously. ${ }^{27,28)}$ Actually, we had tested the statistical power before starting the study based upon the extent of blood pressure reduction from our initial five cases. The mean reduction in blood pressure was $12 \mathrm{mmHg}$, and the expected standard deviation of change was $18 \mathrm{mmHg}$. Therefore, at least 20 cases for each group were needed to achieve statistical significance (power: 0.8 , $\alpha=0.05$ ). The serum nitric oxide and endothelial function did not respond to 10 weeks of enalapril and eprosartan treatment, which conflicts with previous studies. ${ }^{29,30)}$ In fact, we have demonstrated that there are dose-dependent changes in measured parameters after treatment. The significant reductions in indices of 
platelet activation and endothelial damage during high dose treatment support this consideration.

Conclusion: Eprosartan, a novel angiotensin II receptor antagonist, is effective and well tolerated for the treatment of mild to moderate hypertension and results in better diastolic BP control than does enalapril. There were significant dosedependent reductions in indices of platelet activation and endothelial damage in patients with eprosartan and enalapril treatment, and the beneficial effects of these agents were not correlated with the extent of blood pressure reduction in either agent. This may be associated, in part, with the role of angiotensin II in the atherothrombotic process. Further study to delineate the role of blockade of the renin-angiotensin system in atherosclerosis is warranted.

\section{ACKNOWLEDGEMENTS}

We acknowledge the valuable technical assistance provided by Ms. Shu-Chuan Lin and by Pei-Feng Wu in the statistical analysis. This work was supported by grants from the National Science Council (NSC-90-2314-B-075-048).

\section{REFERENCES}

1. Pfeffer MA, Braunwald E, Moye LA, et al. Effect of captopril on mortality and morbidity in patients with left ventricular dysfunction after myocardial infarction. Results of the survival and ventricular enlargement trial. The SAVE Investigators. N Engl J Med 1992; 327: 669-77.

2. Effect of ramipril on mortality and morbidity of survivors of acute myocardial infarction with clinical evidence of heart failure. The Acute Infarction Ramipril Efficacy (AIRE) Study Investigators. Lancet 1993; 342: 821-8.

3. Remme WJ. Bradykinin-mediated cardiovascular protective actions of ACE inhibitors. A new dimension in anti-ischaemic therapy? Drugs 1997; 54 Suppl 5: 59-70.

4. Henrion D, Dechaux E, Dowell FJ, et al. Alteration of flow-induced dilatation in mesenteric resistance arteries of L-NAME treated rats and its partial association with induction of cyclo-oxygenase-2. Br J Pharmacol 1997; 121: 83-90.

5. Oshima S, Ogawa H, Mizuno Y, et al. The effects of the angiotensin-converting enzyme inhibitor imidapril on plasma plasminogen activator inhibitor activity in patients with acute myocardial infarction. Am Heart J 1997; 134: 961-6.

6. Strawn WB, Ferrario CM. Mechanisms linking angiotensin II and atherogenesis. Curr Opin Lipidol 2002; 13 : 505-12.

7. Chen XL, Tummala PE, Olbrych MT, Alexander RW, Medford RM. Angiotensin II induces monocyte chemoattractant protein-1 gene expression in rat vascular smooth muscle cells. Circ Res 1998; 83: 952-9.

8. Tummala PE, Chen XL, Sundell CL, et al. Angiotensin II induces vascular cell adhesion molecule-1 expression in rat vasculature: A potential link between the renin-angiotensin system and atherosclerosis. Circulation 1999; 100: 1223-9.

9. Ferrario CM. Use of angiotensin II receptor blockers in animal models of atherosclerosis. Am J Hypertens 2002; 15: 9S-13S.

10. Gomi T, Ikeda T, Yuhara M, Sakurai J, Nakayama D, Ikegami F. Plasma beta-thromboglobulin to platelet factor 4 ratios as indices of vascular complications in essential hypertension. J Hypertens 1988; 6: 389-92.

11. Ding YA, Chou TC, Lin KC. Effects of long-acting propranolol and verapamil on blood pressure, platelet function, metabolic and rheological properties in hypertension. J Hum Hypertens 1994; 8: 273-8. 
12. Blann AD, Naqvi T, Waite M, McCollum CN. von Willebrand factor and endothelial damage in essential hypertension. J Hum Hypertens 1993; 7: 107-11.

13. Spencer CG, Gurney D, Blann AD, Beevers DG, Lip GY. von Willebrand factor, soluble P-selectin, and target organ damage in hypertension: a substudy of the Anglo-Scandinavian Cardiac Outcomes Trial (ASCOT). Hypertension 2002; 40: 61-6.

14. Wu HD, Katz SD, Beniaminovitz A, Khan T, DiTullio MR, Homma S. Assessment of endothelium-mediated vasodilation of the peripheral circulation by transcutaneous ultrasonography and venous occlusion plethysmography. Heart Vessels 1999; 14: 143-8.

15. Endo T, Imaizumi T, Tagawa T, Shiramoto M, Ando S, Takeshita A. Role of nitric oxide in exercise-induced vasodilation of the forearm. Circulation 1994; 90: 2886-90.

16. Levine B. Eprosartan provides safe and effective long-term maintenance of blood pressure control in patients with mild to moderate essential hypertension. Curr Med Res Opin 2001; 17: 8-17.

17. Bohm M, Sachse A. Safety and tolerability of eprosartan in combination with hydrochlorothiazide. Drug Saf 2002; 25: 599-611.

18. Rake EC, Breeze E, Fletcher AE. Quality of life and cough on antihypertensive treatment: a randomised trial of eprosartan, enalapril and placebo. J Hum Hypertens 2001; 15: 863-7.

19. Piqueras L, Kubes P, Alvarez A, et al. Angiotensin II induces leukocyte-endothelial cell interactions in vivo via AT(1) and AT(2) receptor-mediated P-selectin upregulation. Circulation 2000; 102: 2118-23.

20. Hope S, Brecher P, Chobanian AV. Comparison of the effects of AT1 receptor blockade and angiotensin converting enzyme inhibition on atherosclerosis. Am J Hypertens 1999; 12: 28-34.

21. Ambrosioni E, Bacchelli S, Esposti DD, Borghi C. Anti-ischemic effects of angiotensin-converting enzyme inhibitors: a future therapeutic perspective. J Cardiovasc Pharmacol 2001; 37 Suppl 1: S3-S9.

22. Larsson PT, Schwieler JH, Wallen NH. Platelet activation during angiotensin II infusion in healthy volunteers. Blood Coagul Fibrinolysis 2000; 11: 61-9.

23. Kaplan KL, Owen J. Plasma levels of beta-thromboglobulin and platelet factor 4 as indices of platelet activation in vivo. Blood 1981; 57: 199-202.

24. Goodfield NE, Newby DE, Ludlam CA, Flapan AD. Effects of acute angiotensin II type 1 receptor antagonism and angiotensin converting enzyme inhibition on plasma fibrinolytic parameters in patients with heart failure. Circulation 1999; 99: 2983-5.

25. Nunez A, Gomez J, Zalba LR, et al. Losartan inhibits in vitro platelet activation: comparison with candesartan and valsartan. J Renin Angiotensin Aldosterone Syst 2000; 1: 175-9.

26. Monton M, Jimenez A, Nunez A, et al. Comparative effects of angiotensin II AT-1-type receptor antagonists in vitro on human platelet activation. J Cardiovasc Pharmacol 2000; 35: 906-13.

27. Li-Saw-Hee FL, Beevers DG, Lip GY. Effect of antihypertensive therapy using enalapril or losartan on haemostatic markers in essential hypertension: a pilot prospective randomised double-blind parallel group trial. Int $\mathrm{J}$ Cardiol 2001; 78: 241-6.

28. Blann AD, Lip GY, Islim IF, Beevers DG. Evidence of platelet activation in hypertension. J Hum Hypertens 1997; 11: 607-9.

29. Mancini GB, Henry GC, Macaya C, et al. Angiotensin-converting enzyme inhibition with quinapril improves endothelial vasomotor dysfunction in patients with coronary artery disease. The TREND (Trial on Reversing ENdothelial Dysfunction) Study. Circulation 1996; 94: 258-65.

30. Anderson TJ, Elstein E, Haber H, Charbonneau F. Comparative study of ACE-inhibition, angiotensin II antagonism, and calcium channel blockade on flow-mediated vasodilation in patients with coronary disease (BANFF study). J Am Coll Cardiol 2000; 35: 60-6. 